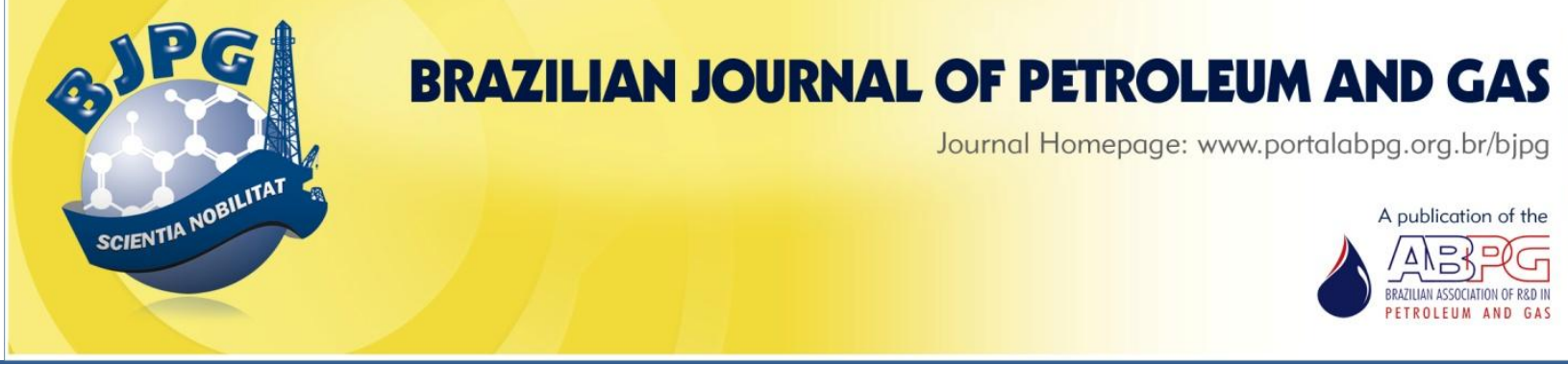

\title{
HYDRAULIC STUDY OF DRILLING FLUID FLOW IN CIRCULAR AND ANNULAR TUBES
}

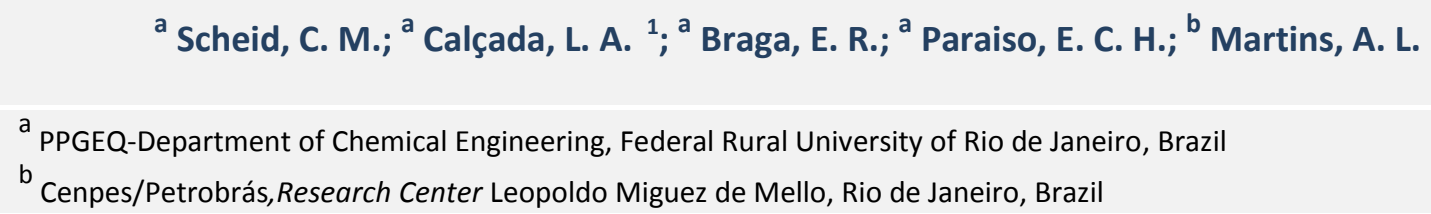

\section{ABSTRACT}

This study investigates the drilling fluid flow behavior of two water-based drilling fluids in circular and annular tubes. The study has four main objectives: 1 ) to evaluate correlations between the Power Law and the Casson rheological models, 2) to characterize the flow behavior, 3) to evaluate five hydraulic-diameter equations, and 4) to evaluate the correlations of five turbulent flow-friction factors. The experimental fluid flow loop consisted of one positive displacement pump of $25 \mathrm{HP}$ connected to a 500-liter tank agitated by a 3-HP mixer. The fluids passed through six meters long tubes, arranged in three horizontal rows with independent inlets and outlets. The circular tubes had a 1 inch diameter and were configured as two concentric annular tubes. Annular Tube I had an outer diameter of $1 \frac{114}{4}$ inch and an inner diameter of $1 / 2$ inch. Annular Tube II had an outer diameter of 2 inches and an inner diameter of $3 / 4$ inch. The results show that, for the fluids in exam, correlations proposed in the literature were inaccurate as far as predicting hydraulic diameter, estimating pressure drop, and defining the flow regime. In general, the performance of those correlations depended on the fluid properties and on the system's geometry. Finally, literature parameters for some of the correlations were estimated for the two drilling fluids studied. These estimations improved the predictive capacity of calculating the friction factor for real drilling fluids applications for both circular and annular tubes.

\section{KEYWORDS}

friction factor; hydraulic diameter; rheological model; critical Reynolds number

\footnotetext{
${ }^{1}$ To whom all correspondence should be addressed. Address: PPGEQ-Department of Chemical Engineering, Federal Rural University of Rio de Janeiro, BR 465, Km 7, Campus da UFRRJ, CEP:23890-000, Seropédica-RJ, Brazil Telephone/Fax: +55 21 37878742/+55 21 37873750| E-mail: calcada@ufrri.br doi:10.5419/bjpg2011-0023
} 


\section{INTRODUCTION}

A well drilling process involves drilling fluids that exhibit non-Newtonian behavior. These fluids flow along the drilling columns and within the annular ring formed by the column and the well's wall. A good estimation of the pressure drop or the friction loss coefficient is relevant to projecting hydraulic and pumping systems and, moreover, to controlling bottom pressure during operation.

Oil and gas wells are both expensive and risky to drill. Researchers, aiming to optimize energy costs and operation control, have taken a keen interest in drilling fluid behavior. Drilling fluids, especially those with non-Newtonian characteristics, have many formulations. Out of the drilling fluid's four basic functions, its primary one is to exert hydrostatic pressure over the permeable formations. This helps prevent the formation's fluids from invading the well during drilling operations. A second function of drilling fluids is to remove gravel formed by fractured rocks. The other two functions are to cool and lubricate the drill. Fluid pressure is normally kept above the formation's pore pressure to prevent kick events. Kick events, in some cases, can lead to an uncontrolled influx, commonly called as blowout.

Bourgoyne et al. (1991) discussed the importance of tightly controlling the velocity and pressure of the flow along the well. A high velocity may cause erosion while a low velocity may be insufficient to transport the gravel. At the same time, excessive pressure can lead to fractured rocks and excessive invasion. Insufficient pressure can lead to the inner fluids of the rocks refluxing into the well, generating kicks or blowouts.

The literature discusses the flow of nonNewtonian fluids in tubes using different rheological models. Bertola and Cafaro (2003) used three models of non-Newtonian fluid. Using the Power Law model, Escudier et al. (2002) studied the flow of shear-thinning fluid through annular tubes. Huilgol (2006) developed a systematic process to determine, in ducts with symmetrical cross sections, the lowest pressure drop on the flow of viscoelastic fluids.

This work determines the friction factor and pressure drop of two real water-based drilling fluids in circular and concentric annular tubes. In regard to the hydraulic project and the design of the well, experimental data permitted the evaluation of the friction factor correlations available in the literature. The data also permitted the evaluation of the limits of flow as well as the hydraulic diameter equations. The Power Law and the Casson models were adopted to describe the fluids' rheological behavior. The Power Law model is widely used in the petroleum industry to describe fluid behavior. The Casson model is important when the fluid behavior presents yield stress. To calculate the drilling fluid's pressure drop in the tubes, analyses were done of the flow regimes, five hydraulic diameter equations and correlations for friction factors. The new parameters were proposed for the literature's friction factor correlations considering the applications involving these fluids and the need for an equation that would improve hydraulic projects.

\section{CORRELATION TO CALCULATE FRICTION FACTOR, HYDRAULIC DIAMETER AND FLOW REGIME}

\subsection{Rheological models and generalized Reynolds number}

Frequently, drilling fluid's rheological behavior is described by employing the Power Law and the Casson models, as in Equations 1 and 2.

$\tau=\mathrm{k} \gamma^{\mathrm{n}}$

$\tau=\left(\mu_{\mathrm{p}} \gamma\right)^{\frac{1}{2}}+\tau_{0}^{\frac{1}{2}}$

where $\tau$ is the shear stress, $\gamma$ is the shear rate, $k$ and $\mathrm{n}$ are the fluid consistency and fluid behavior index of the power law model, $\mu_{p}$ and $\tau_{0}$ are the plastic viscosity and yield stress of the Casson model.

The parameters of the Power Law and Casson models can be calculated by linear regression, plotting shear stress versus shear rate data. For the Power Law model, Metzner and Reed (1955) proposed Equation 3 as a modified Reynolds number. For the Casson model, the Reynolds number is calculated by Equation 4 . 


$$
\operatorname{Re}=\frac{(\operatorname{Dv} \rho)}{k\left(\frac{8 v}{D}\right)^{n-1}\left(\frac{3 n+1}{4 n}\right)^{n}}
$$

$\operatorname{Re}=\frac{\operatorname{Dv} \rho}{\mu_{\mathrm{p}}}$

where $D$ is the diameter of the circular tube or the hydraulic diameter for the annular tube, $v$ is the fluid's average velocity, and $\rho$ is the fluid's density.

Fluids with yield stress require another dimensionless number called Hedstrom, He. For the Casson model, the Hedstrom number is defined by Equation 5 .

$$
\mathrm{He}=\frac{\mathrm{D}^{2} \rho \tau_{0}}{\mu_{\mathrm{p}}}
$$

\subsection{Definition of flow regimes}

The critical Reynolds number (Rec) defines the transition between laminar and turbulent flow. The limits of each flow regime may be calculated through experimental plots of pressure drop versus volumetric flow. In these experimental curves, changes in slope indicate the limits between flow regimes. Using this technique, one can obtain the critical flow, which may be used to calculate the critical Reynolds number. Each critical Reynolds number must be calculated in accordance to each rheological model.

Ryan and Johnson (1959) proposed Equation 6 to formulate a general criterion to characterize the flow regime.

$\operatorname{Rec}=\frac{6464 n}{(1+3 n)^{2}(2+n)^{-\frac{(2+n)}{(1+n)}}}$

where $\mathrm{n}$ is the rheological parameter of the Power Law model.

Intuitive physical arguments suggested the use of a local flow stability parameter as a way to characterize the flow regime. Such a parameter is a function of the ratio between the fluid's energy input and energy dissipation. This inference has been verified for several pseudoplastic fluids. For flows in tubes, Ryan and Johnson (1959) and Hanks (1963) proposed a stability parameter $X_{C}$ (Equation 7). They proposed a generalized stability parameter considering isothermal flow and Power Law model. The parameter, independent of the geometry of the flow system, is obtained from studies of the Reynolds number for Newtonian flows. Equation 8 can be used to calculate Rec.

$$
\begin{aligned}
& \frac{X_{c}}{\left(1-X_{c}\right)^{3}}=\frac{H e}{16800} \\
& \operatorname{Rec}=\left(\frac{H e}{8 X_{c}}\right)\left(1-\frac{4}{3} X_{c}+\frac{1}{3} X_{c}{ }^{4}\right)
\end{aligned}
$$

Mishra and Tripathi (1971) developed Equation 9 by using the criterion for the stability parameter for laminar flows of purely viscous non-Newtonian fluids. A generalized relation for the laminar flow was obtained from the derivation of dimensionless groups.

$$
\operatorname{Rec}=2100 \frac{(4 n+2)(5 n+3)}{3(3 n+1)^{2}}
$$

The critical velocity characterizes the flow regime of non-Newtonian fluids with yield stress. Craft (1962) and Thomas (1963) proposed Equations 10 and 11 to calculate critical velocity. For Thomas' equation, $v_{c}$ is a function of the Newtonian critical Reynolds.

$\mathrm{v}_{\mathrm{c}}=\left(\frac{\operatorname{Re} \tau_{0}}{6 \rho}\right)^{\frac{1}{2}}$

$\mathrm{v}_{\mathrm{c}}=\frac{\left(1.078 \mu_{\mathrm{p}}+1.078\left(\mu_{\mathrm{p}}^{2}+12.34 \mathrm{D}^{2} \tau_{0 \rho}\right)^{\frac{1}{2}}\right.}{\rho \mathrm{D}}$

where $\mu_{p}$ is the plastic viscosity and the yield stress of the Casson model.

\subsection{Hydraulic Diameter}

Five equations were investigated to calculate the hydraulic diameter. The first one $\left(D_{\mathrm{H} 1}\right)$ was developed analytically, considering the annular region formed by two concentric cylinders as a fissure formed by two plane plates. This theory, known as Slot, generated Equation 12. Its considerations are valid when the ratio between the internal and external diameter is greater than 0.3 (Bourgoyne et al., 1991).

$\mathrm{D}_{\mathrm{H} 1}=0.816\left(\mathrm{D}_{2}-\mathrm{D}_{1}\right)$ 
The second equation $\left(D_{\mathrm{H} 2}\right)$ was developed analytically from the theory of the hydraulic radius (Bourgoyne et al., 1991). The ratio of the area between the cross section and the wet perimeter of the annular region determines the hydraulic diameter, which is equivalent to four times the value of the hydraulic radius, as seen in equation 13.

$\mathrm{D}_{\mathrm{H} 2}=4 \mathrm{R}_{\mathrm{H}}=\mathrm{D}_{2}-\mathrm{D}_{1}$

The third equation $\left(D_{\mathrm{H} 3}\right)$, depicted as Equation 14 , was developed by Lamb (1945). This equation is used to predict friction loss for Newtonian fluid flows in circular and annular tubes.

$\mathrm{D}_{\mathrm{H} 3}=\sqrt{\mathrm{D}_{2}^{2}+\mathrm{D}_{1}^{2}-\frac{\mathrm{D}_{2}^{2}-\mathrm{D}_{1}^{2}}{\ln \left(\frac{\mathrm{D}_{2}}{\mathrm{D}_{1}}\right)}}$

Crittendon (1959) obtained Equation 15 from an empirical work using hundreds of diameter ratios. For academic purposes Equation 15 is called hereafter $\mathrm{D}_{\mathrm{H} 4}$.

$\mathrm{D}_{\mathrm{H} 4}=\frac{\sqrt[4]{\mathrm{D}_{2}{ }^{4}-\mathrm{D}_{1}{ }^{4}-\frac{\left(\mathrm{D}_{2}{ }^{2}-\mathrm{D}_{1}{ }^{2}\right)^{2}}{\ln \left(\frac{\mathrm{D}_{2}}{\mathrm{D}_{1}}\right)}}+\sqrt{\mathrm{D}_{2}{ }^{2}-\mathrm{D}_{1}{ }^{2}}}{2}$

Pilehvari and Serth (2005) developed Equation $16\left(D_{\text {H5 }}\right)$. Their model started with Lamb's definition of the hydraulic diameter (Lamb, 1945). This equation is also based on the solution of the Navier-Stokes equation for the concentric annular tubes.

$D_{H 5}=\left(D_{2}-D_{1}\right) \frac{\left[1+\left(\frac{D_{1}}{D_{2}}\right)^{2}+\frac{\left(1-\left(\frac{D_{1}}{D_{2}}\right)^{2}\right)}{\ln \left(\frac{D_{1}}{D_{2}}\right)}\right]}{\left(1-\left(\frac{D_{1}}{D_{2}}\right)^{2}\right)}$

\subsection{Friction factor correlations}

There are several correlations in the literature for calculating the friction factor for the flow of non-Newtonian fluids in turbulent flows. Equations 17 through 19 show the correlations between the Fanning friction factor, $f$, under turbulent flow and pseudoplastic fluids following the Power Law model. Those equations, proposed by Gomes (1987), made $f$ explicit from equations originally proposed by Dodge and Metzner (the DMGomes- equation 17), Ostwald de Waele ( the OWGomesequation 18), and Frank Schuh (the FSGomesequation 19), respectively.

$\mathrm{f}=0.060 \mathrm{n}^{0.462} \mathrm{Re}^{-0.233}$

$\mathrm{f}=0.069 \mathrm{n}^{0.666} \mathrm{Re}^{-0.235}$

$\mathrm{f}=0.110 \mathrm{n}^{0.616} \mathrm{Re}^{-0.287}$

Equations 20 through 28 can be used to calculate the friction factor for fluids that have yield stress. They may also be used by the Casson model. Tomita (1959) proposed Equations 20 and 21 in his study of Bingham fluids flow in circular ducts of different diameters.

$\mathrm{f}=\frac{\lambda}{4}$

where,

$\frac{1}{\sqrt{\lambda}}=2 \log \left(\operatorname{Re} \frac{\sqrt{\lambda}}{2}\right)-0.2$

For flows of Bingham fluids in tubes, Darby and Melson (1981) proposed Equation 22.

$\mathrm{f}=\left(\mathrm{f}_{\mathrm{L}}^{\mathrm{m}}+\mathrm{f}_{\mathrm{T}}^{\mathrm{m}}\right)^{\frac{1}{\mathrm{~m}}}$

$\mathrm{f}_{\mathrm{L}}^{\mathrm{m}}=\frac{16}{\operatorname{Re}}\left(1+\frac{\mathrm{He}}{6 \mathrm{Re}}-\frac{\mathrm{He}^{4}}{3 \mathrm{f}^{3} \mathrm{Re}^{7}}\right)$

$\mathrm{f}_{\mathrm{T}}^{\mathrm{m}}=\frac{10^{\mathrm{a}}}{\operatorname{Re}^{0.289}}$

$\mathrm{a}=-1.378\left(1+0.14 \exp \left(-2.9 \times 10^{-5} \mathrm{Re}\right)\right)$

$\mathrm{m}=1.7+\frac{40000}{\operatorname{Re}}$

Darby et al. (1992) proposed changes to this equation, leading to Equation 27. 


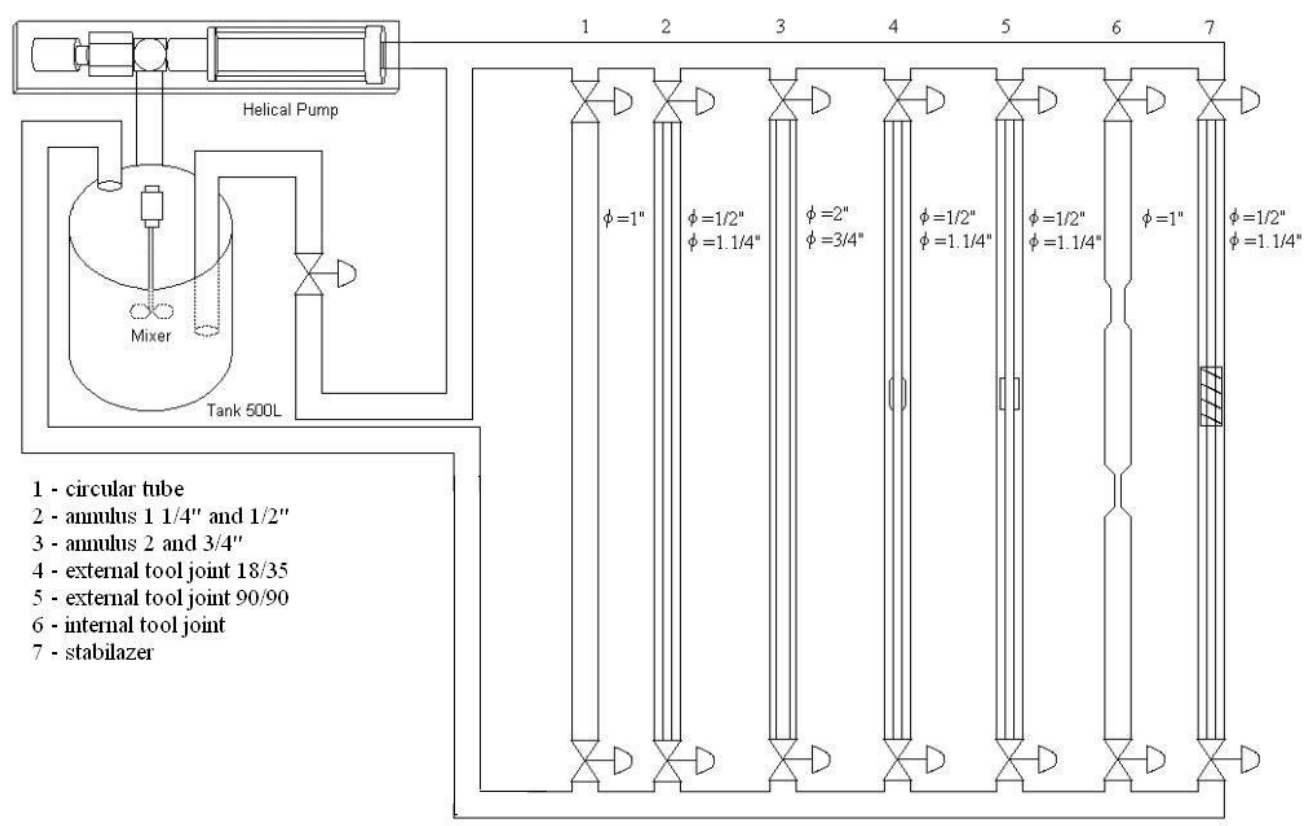

Figure 1. Scheme of the experimental fluid flow loop.

$\mathrm{f}=\frac{10^{\mathrm{a}}}{\operatorname{Re}^{0.193}}$

$\mathrm{a}=-1.47\left(1+0.146 \exp \left(-2.9 \times 10^{-5} \mathrm{He}\right)\right)$

Ellis and George (1977) and Churchill (1977) proposed Equations 29 and 30, respectively. These equations are applied to pseudoplastic fluids adjusted by the Power Law model, and also to fluids that have yield stress as a parameter of rheological behavior, similarly to what occurs with the Casson model.

$f=0.00454+0.645 R e^{0.70}$

$f=2\left(\left(\frac{8}{\operatorname{Re}}\right)^{12}+\frac{1}{(A+B)^{\frac{3}{2}}}\right)^{\frac{1}{12}}$

Where,

$A=\left(2.457 \ln \left(\frac{1}{\left(\frac{7}{\operatorname{Re}}\right)^{0.9}+0.27\left(\frac{\varepsilon}{\mathrm{D}}\right)}\right)\right)^{16}$
$\mathrm{B}=\left(\frac{37530}{\mathrm{Re}}\right)^{16}$

and $\varepsilon$ is the roughness.

\section{MATERIALS AND METHODS}

A multipurpose fluid flow loop made up of circular and annular tubes was constructed. The diameters of the tubes and pumping capacity were projected in a way that the experimental tests would be a dynamic representation of a drilling fluid flow in the field. In this loop, it was possible to maneuver the fluid through the circular and annular tubes.

The tubes were made of galvanized iron and the loop was operated in a closed circuit. For the Reynolds number, the fluid flow loop operated in a range of 500 to 5,000 . The reason for all these efforts was to maintain the geometrical and dynamical similarity between the experimental unit and field conditions. The fluids flowed in six-meter long tubes arranged in six rows with independent inlets and outlets, Figure 1. This experiment observed the operation of only three of these rows, composed of one circular 1 inch diameter tube and of two concentric annular tubes. Annular I had an outer diameter of $1 \frac{1}{4}$ inch and an inner diameter of a $1 / 2$ inch. Annular II had an outer 


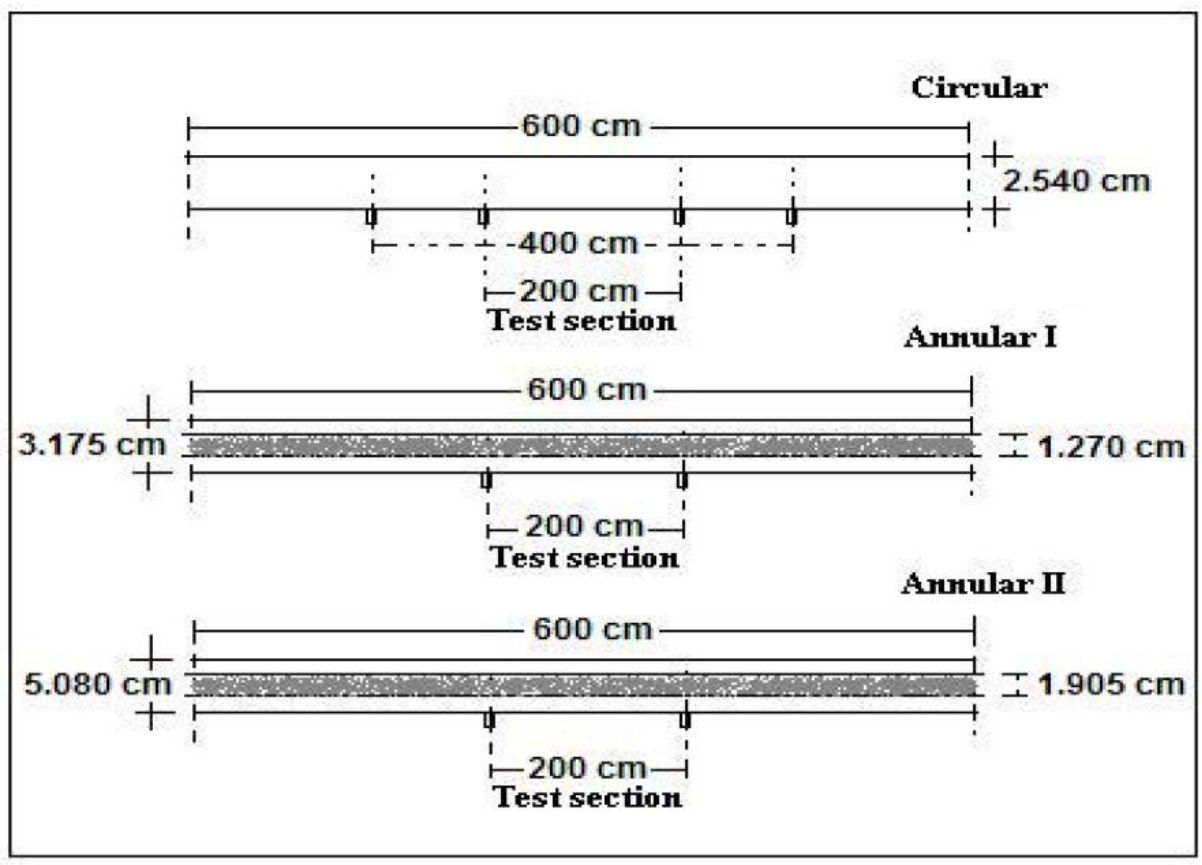

Figure 2. Information about the tubes' geometries.

diameter of 2 inches and an inner diameter of $3 / 4$ inch. In petroleum drilling fields, Annular I had a ratio of $12 \frac{1}{4}$ inches to $5 \frac{1}{2}$ inches and Annular II had a ratio of $8 \frac{1}{2}$ inches to 5 inches. The first diameter dimension represents the diameter of the well and the second one the diameter of the drilling column. The tube rows were connected to a 500 liter stainless steel tank, equipped with a $3 \mathrm{HP}$ vertical mixer.

The fluid displacement was performed by a 25 HP (Weatherford) positive displacement helical pump. The pump operated with flow rates of up to $20 \mathrm{~m}^{3} / \mathrm{h}$ and a maximum operational pressure of up to $12 \mathrm{kgf} / \mathrm{crn}^{2}$. Figure 1 shows a sketch of the experimental unit.

Differential pressure gauges, with ranges of 0 $35 \mathrm{mmHg}, 0-350 \mathrm{mmHg}$, and 0-950 $\mathrm{mmHg}$, were used to register the pressure drop of the fluid flow. The pressure plugs, where the pressure was transmitted to the gauges, were positioned at least 60 diameters away from the entry and exit regions of each tube. The gravimetric technique was used to determine, in triplicate, the flow rate. Figure 2 presents the dimensions of the circular and two annular concentric tubes. It also shows the sections where the pressure drops were taken. For the circular tube exclusively, double of the test's section was used to provide a greater collection of flow rates during the experiment.
The non-Newtonian pseudo-plastic fluids, named 1 and 2, were provided by Petrobras. The Brazilian petroleum company provided a 1000-liter sample of each fluid from its production fields. These fluids had been used in drilling operations in Brazilian oil fields. The fluids were water based, constituted basically of polymeric solutions (Xanthan gum and cationic polymer), cationic surfactant, amide, potassium chloride and calcite. To protect the company's confidentiality, the concentrations of each component were omitted. The density of the fluids was obtained by picnometry. The values obtained were $1150 \mathrm{Kg} / \mathrm{m}^{3}$ for Fluid 1 and $1100 \mathrm{Kg} / \mathrm{m}^{3}$ for Fluid 2 .

During the experiments, the temperature of the fluids ranged from $21^{\circ} \mathrm{C}$ to $48^{\circ} \mathrm{C}$. In this case, the temperature effect was evaluated through the rheological determination of each experimental point using a FANN viscometer, model 35A. Fluid samples were collected from the tank at the same time that the fluid flow and pressure drop were recorded.

The viscometer worked with six frequency options, varying from 3 to $600 \mathrm{rpm}$, with shear rates ranging between $5.1 \mathrm{~s}^{-1}$ and $1022 \mathrm{~s}^{-1}$, respectively. The values of shear stress depend on the fluid properties. For Fluid 1, the minimum value was $4.56 \mathrm{~kg} / \mathrm{ms}^{2}$ and the maximum $30.149 \mathrm{~kg} / \mathrm{ms}^{2}$. For Fluid 2, the values ranged from $1.02 \mathrm{~kg} / \mathrm{ms}^{2}$ to 
Table 1. Range of parameters for the Power Law rheological model.

\begin{tabular}{ccccc}
\hline \multirow{2}{*}{ Parameter } & \multicolumn{2}{c}{ Fluid 1 } & \multicolumn{2}{c}{ Fluid 2 } \\
\cline { 2 - 5 } & Minimum Value & Maximum Value & Minimum Value & Maximum Value \\
\hline$N$ & 0.2291 & 0.2977 & 0.3885 & 0.5200 \\
$k\left(\mathrm{~kg} / \mathrm{m} . \mathrm{s}^{2-\mathrm{n}}\right)$ & 2.8379 & 4.6761 & 0.4068 & 1.0427 \\
$\mathrm{R}^{2}$ & \multicolumn{2}{c}{0.9950} & & \multicolumn{2}{c}{0.9959} \\
\hline
\end{tabular}

Table 2. Range of parameters for the Casson rheological model.

\begin{tabular}{ccccc}
\hline \multirow{2}{*}{ Parameter } & \multicolumn{2}{c}{ Fluid 1 } & \multicolumn{2}{c}{ Fluid 2 } \\
\cline { 2 - 5 } & Minimum Value & Maximum Value & Minimum Value & Maximum Value \\
\hline$\tau_{0}\left(\mathrm{~kg} / \mathrm{m}_{\mathrm{s}} \mathrm{s}^{2}\right)$ & 4.6195 & 6.6926 & 0.7829 & 1.8201 \\
$\mu_{\mathrm{p}}(\mathrm{kg} / \mathrm{m} . \mathrm{s})$ & 0.0059 & 0.0091 & 0.0073 & 0.0130 \\
$\mathrm{R}^{2}$ & & 0.9725 & \multicolumn{2}{c}{0.9831} \\
\hline
\end{tabular}

$20.951 \mathrm{~kg} / \mathrm{ms}^{2}$. Tables 1 and 2 show the minimum and maximum values of rheological parameters adjusted for each model and the Square Pearson correlation coefficient. The Power Law model had the highest coefficient for the square correlation of Fluids 1 and 2 .

\section{RESULTS AND DISCUSSION}

\subsection{Determination of flow regimes}

For typical results, Figure 3 shows the differential pressure versus volumetric flow rate for Fluid 1 flowing in a circular tube. The slope of the straight lines generated by the experimental points changed at a certain point. This behavior, defined by the critical flow point, indicated that the flow regime was changing from laminar to turbulent regimes. Metzner and Reed (1955) described two critical points: the first one defines the end of the laminar regime and the second one defines the beginning of the turbulent regime. Between the critical points there was a transition zone.

For Fluid 1, flowing in the circular tube, the critical flow point appeared when the flow rate reached $0.00275 \mathrm{~m}^{3} / \mathrm{s}$, Figure 3 . For instance, for Annular I and the same fluid, critical flow occurred when $0.00225 \mathrm{~m}^{3} / \mathrm{s}$ was reached. For Annular II, no critical flow was observed and the data was in laminar flow. For Fluid 2, the critical points were at $0.001293 \mathrm{~m}^{3} / \mathrm{s}$, at $0.001559 \mathrm{~m}^{3} / \mathrm{s}$, and at 0.003373 $\mathrm{m}^{3} / \mathrm{s}$ for the circular tube, Annular I and Annular II, respectively.

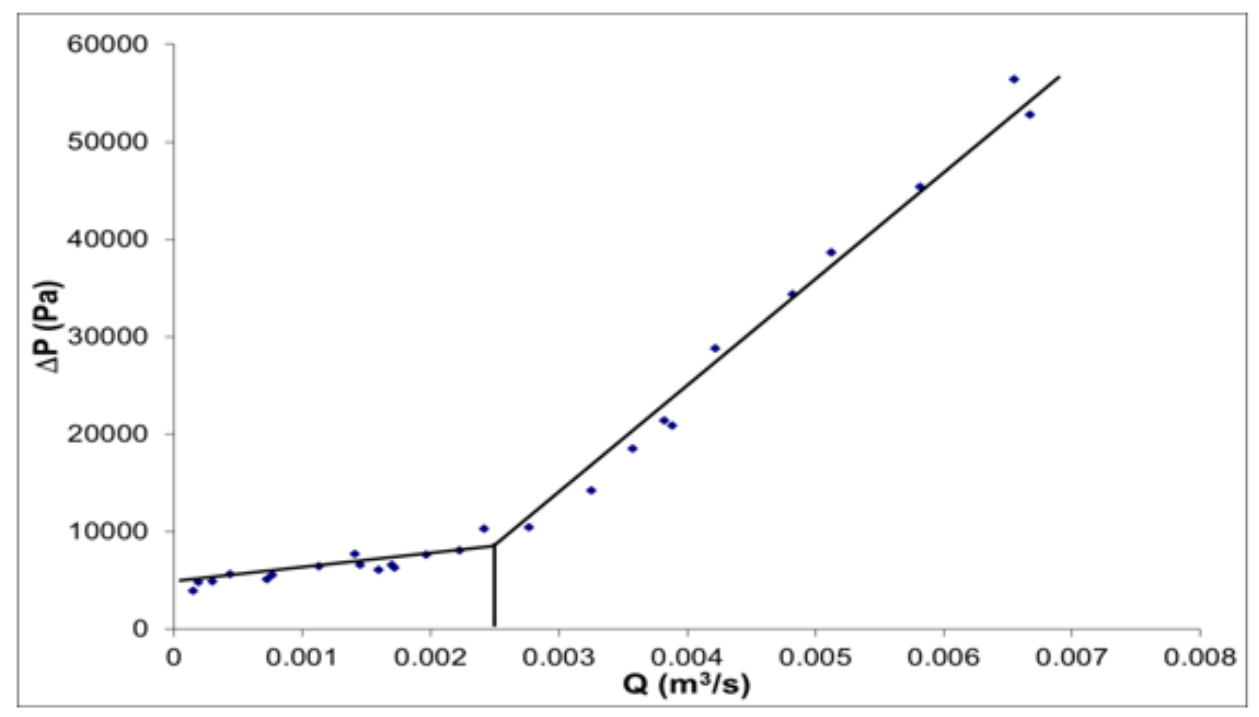

Figure 3. Critical flow regime for Fluid 1 in circular. 
Table 3. Hydraulic diameter values for the annular tubes.

\begin{tabular}{lcc}
\hline \multicolumn{1}{c}{ Correlation } & Annular I $(\mathrm{m})$ & Annular II $(\mathrm{m})$ \\
\hline Slot $\left(D_{H 1}\right)$ & 0.0122 & 0.0220 \\
Hydraulic radius $\left(D_{H 2}\right)$ & 0.0150 & 0.0270 \\
Lamb $\left(D_{H 3}\right)$ & 0.0123 & 0.0221 \\
Crittendon $\left(D_{H 4}\right)$ & 0.0242 & 0.0394 \\
Pilehvari and Serth $\left(D_{H 5}\right)$ & 0.0100 & 0.0181 \\
\hline
\end{tabular}

Table 4. Results of the experimental critical Reynolds number.

\begin{tabular}{ccccc}
\hline \multirow{2}{*}{ Geometry } & \multicolumn{2}{c}{ Fluid 1 } & \multicolumn{2}{c}{ Fluid 2 } \\
\cline { 2 - 5 } & $\begin{array}{c}\text { Power Law } \\
\text { Model }\end{array}$ & $\begin{array}{c}\text { Casson } \\
\text { Model }\end{array}$ & $\begin{array}{c}\text { Power Law } \\
\text { Model }\end{array}$ & Casson Model \\
\hline Circular & 7477 & 21597 & 3018 & 7045 \\
Annular I ( $\left.D_{\mathrm{H} 1}\right)$ & 3057 & 6234 & 2246 & 3400 \\
Annular I ( $\left.D_{\mathrm{H} 2}\right)$ & 3228 & 7640 & 2457 & 4167 \\
Annular I ( $\left.D_{\mathrm{H} 3}\right)$ & 3060 & 6253 & 2249 & 3410 \\
Annular I ( $\left.D_{\mathrm{H} 4}\right)$ & 3668 & 12324 & 3033 & 6721 \\
Annular I ( $\left.D_{\mathrm{H} 5}\right)$ & 2901 & 5118 & 2059 & 2791 \\
Annular II ( $\left(D_{\mathrm{H} 1}\right)$ & & & 2370 & 5492 \\
Annular II ( $\left.D_{\mathrm{H} 2}\right)$ & & & 2588 & 6731 \\
Annular II ( $\left(D_{\mathrm{H} 3}\right)$ & & & 2374 & 5517 \\
Annular II ( $\left.D_{\mathrm{H} 4}\right)$ & & & 3049 & 9820 \\
Annular II ( $\left(D_{\mathrm{H} 5}\right)$ & & & 2178 & 4523 \\
\hline
\end{tabular}

Table 5. Critical Reynolds number's relative error using Power Law model and Ryan and Johnson's (1959) and Mishra and Tripathi's (1971) correlations.

\begin{tabular}{|c|c|c|c|c|c|c|c|c|}
\hline \multirow{3}{*}{ Geometry } & \multicolumn{4}{|c|}{ Ryan and Johnson } & \multicolumn{4}{|c|}{ Mishra and Tripathi } \\
\hline & \multicolumn{2}{|c|}{ Fluid 1} & \multicolumn{2}{|c|}{ Fluid 2} & \multicolumn{2}{|c|}{ Fluid 1} & \multicolumn{2}{|c|}{ Fluid 2} \\
\hline & $\operatorname{Rec}_{\exp }$ & $\sigma(\%)$ & $\operatorname{Rec}_{\exp }$ & $\sigma(\%)$ & $\operatorname{Rec}_{\text {exp }}$ & $\sigma(\%)$ & $\mathrm{Rec}_{\text {exp }}$ & $\sigma(\%)$ \\
\hline Circular & 2301 & -69.2 & 2394 & -22.7 & 2870 & -61.6 & 2533 & -16.1 \\
\hline Annular I $\left(D_{\mathrm{H} 1}\right)$ & 2301 & -24.7 & 2394 & 6. & 2870 & -6.1 & 2533 & 12.8 \\
\hline Annular I ( $\left.D_{\mathrm{H} 2}\right)$ & 2301 & -28.7 & 2394 & -2 & 2870 & -11.1 & 2533 & 3.1 \\
\hline Annular I $\left(D_{\mathrm{H}_{3}}\right)$ & 2301 & -24.8 & 2394 & 6.5 & 2870 & -6.2 & 2533 & 12.6 \\
\hline Annular I $\left(D_{\mathrm{H} 4}\right)$ & 2301 & -37.3 & 2394 & -21.1 & 2870 & -21.8 & 2533 & -16.5 \\
\hline Annular I $\left(D_{H 5}\right)$ & 2301 & -20.7 & 2394 & 16.3 & 2870 & -1.1 & 2533 & 23.0 \\
\hline Annular & & & 2394 & 1.0 & & & 2533 & 6.9 \\
\hline Annular II $\left(\mathrm{D}_{\mathrm{H} 2}\right)$ & & & 2394 & -7.5 & & & 2533 & -2.1 \\
\hline Annular II $\left(D_{\mathrm{H} 3}\right)$ & & & 2394 & 0.9 & & & 2533 & 6.7 \\
\hline Annular II $\left(D_{\mathrm{H}_{4}}\right)$ & & & 2394 & -21.5 & & & 2533 & -16.9 \\
\hline Annular II $\left(D_{H 5}\right)$ & & & 2394 & 9.9 & & & 2533 & 16.3 \\
\hline
\end{tabular}

In order to calculate the Rec of Annular I and II at the critical flow, it is necessary to use correlations for the hydraulic diameter. Five hydraulic diameter correlations were evaluated in this work. Table 3 presents the calculated values for the critical points. It emphasizes the similarities between the values of $D_{H 1}$ and $D_{H 3}$ for Annular I and II.
Table 4 shows the results of the experimental Rec number using different correlations of the hydraulic diameter. The analysis of this data indicates that the values of Rec depend on the choice of the correlation for hydraulic diameter. In this investigation, using an improper equation for the hydraulic diameter may cause significant errors in the friction factors. Moreover, the Reynolds number obtained by the Casson model was 
Table 6. Critical Reynolds number's relative error using the Power Law model and correlations of Hanks, Craft and Thomas.

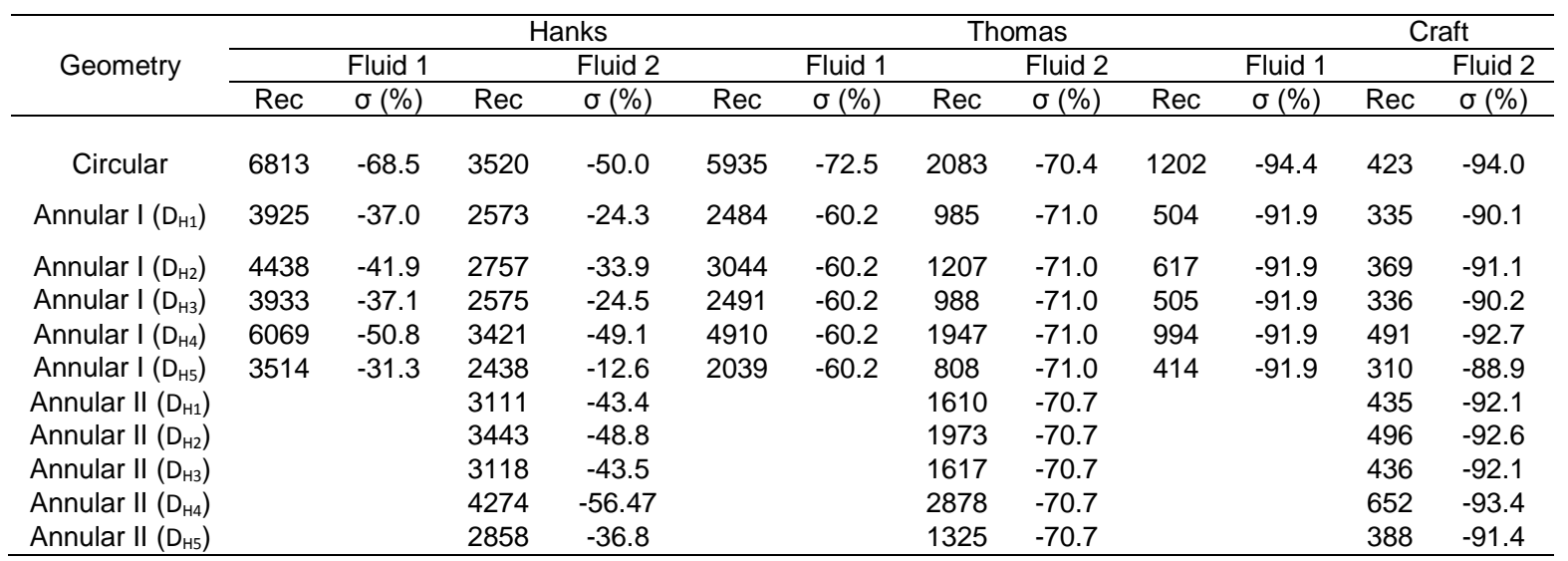

frequently higher than the one obtained by the Power Law model. The disparity was caused by using two different rheological models representing the same experimental data. Each model has a specific equation to calculate the Reynolds number.

Table 5 shows the relative error for the correlations of Ryan and Johnson (1959) and Mishra and Tripathi (1971) using the Power Law model for the fluid's rheology. The values showed in Table 5 are the calculated one. The relative error is calculated according to Equation 33.

$\sigma=\frac{100(\mathrm{Ev}-\mathrm{Vc})}{\mathrm{Ev}}$

where $\sigma$ is the relative error, Ev is the experimental value and $V_{c}$ is the value obtained from the correlation.

The correlations of Ryan and Johnson (1959) and Mishra and Tripathi (1971) depend only on the rheological parameter $\mathrm{n}$ from the Power Law model and contain no information about flow geometry.

The correlations of Hanks (1963), Craft (1962), and Thomas (1963) depend on the adopted geometry. In this case, it is necessary to calculate the Rec number for each tube analyzed.

Using the Power Law and Casson models for the circular tube, none of the correlations yielded satisfactory results. For Fluid 1, adopting the Power
Law model and flow through Annular I, Mishra and Tripathi's equation gave satisfactory results of about $6 \%$ using the hydraulic diameter equations $D_{H_{1}}$ and $D_{H 3}$, about $11 \%$ using equation $D_{H_{2}}$ and about $1 \%$ using the $\mathrm{D}_{\mathrm{H} 5}$ correlation.

For Fluid 2, when adopting the Power Law model and flow through annular I and II, Ryan and Johnson's equation achieved better performance in the first three hydraulic diameter correlations. For the other two correlations, considerable errors arose. Even larger deviations were found with Mishra and Tripathi's equation. When the Casson model for the annular tubes was adopted none of the proposed correlations presented good results. Critical Reynolds numbers were calculated using correlations of Hanks, Craft and Thomas. Table 6 shows the relative error between correlations and the experimental data obtained using the Power Law model.

\subsection{Evaluation of the hydraulic diameter correlations}

Equation 34 was used to evaluate the hydraulic diameter correlations by comparing the pressure drop measured experimentally with the one calculated for the annular tubes in laminar flow. In this equation, $D$ is the value of the hydraulic diameter used by one of the correlations and $f$ is the Fanning friction factor in laminar flow.

$\Delta \mathrm{P}=\frac{\mathrm{f} \rho \mathrm{Lv}^{2}}{2 \mathrm{D}}$ 
Table 7. Average absolute error for the calculated pressure drop using correlations of hydraulic diameters for Fluid 1.

\begin{tabular}{ccccc}
\hline \multirow{3}{*}{ Hydraulic diameter } & \multicolumn{4}{c}{$\sigma(\%)$} \\
\cline { 2 - 5 } & \multicolumn{2}{c}{ Power Law } & \multicolumn{2}{c}{ Casson } \\
\cline { 2 - 5 } & Annular I & Annular II & Annular I & Annular II \\
\hline$D_{\mathrm{H} 1}$ & 26.18 & 9.06 & 28.85 & 11.41 \\
$D_{\mathrm{H} 2}$ & 25.85 & 21.53 & 15.83 & 24.70 \\
$D_{\mathrm{H} 3}$ & 26.09 & 8.96 & 27.64 & 11.25 \\
$D_{\mathrm{H} 4}$ & 51.52 & 51.15 & 52.76 & 54.85 \\
$D_{\mathrm{H} 5}$ & 47.41 & 30.96 & 74.95 & 33.47 \\
\hline
\end{tabular}

Table 8. Average absolute deviance for the calculated pressure drop using the correlations of hydraulic diameters for Fluid 2.

\begin{tabular}{ccccc}
\hline \multirow{2}{*}{ Hydraulic diameter } & \multicolumn{4}{c}{$\sigma(\%)$} \\
\cline { 2 - 5 } & \multicolumn{3}{c}{ Power Law } & \multicolumn{2}{c}{ Casson } \\
\cline { 2 - 5 } & Annular I & Annular II & Annular I & Annular II \\
\hline$D_{\mathrm{H} 1}$ & 16.30 & 19.18 & 22.11 & 6.35 \\
$D_{\mathrm{H} 2}$ & 13.73 & 11.14 & 15.85 & 22.95 \\
$D_{\mathrm{H} 3}$ & 15.84 & 18.40 & 21.69 & 5.76 \\
$D_{\mathrm{H} 4}$ & 56.26 & 48.50 & 59.93 & 56.51 \\
$D_{\mathrm{H} 5}$ & 54.06 & 57.77 & 68.63 & 43.35 \\
\hline
\end{tabular}

Calculating the friction factor depended on the rheological model adopted. The hydraulic diameter equations were evaluated for each rheological model. To calculate the friction factor for the Power Law model Equation 35 was used and for the Casson model Equation 36 was applied.

$f=\frac{16}{\operatorname{Re}}$

$f=\frac{16}{\operatorname{Re}}\left(1-\frac{\mathrm{He}}{6 \mathrm{Re}}+\frac{\sqrt{2 \mathrm{fHe}}}{7}+\frac{\mathrm{He}^{4}}{21 \mathrm{f}^{3} \operatorname{Re}^{7}}\right)$

As typical data samples, Tables 7 and 8 show the average absolute error between the pressure drop calculated for Fluids 1 and 2 and the experimental data. Figure 4 presents experimental data for evaluation of hydraulic diameter correlations using Power Law for Annular II. According to the results found in Tables 6 and 7, the correlations proposed by Crittendon (1959) and Pilehvari and Serth (2005) are inadequate for neither the fluids nor the annular ratios. The correlations $D_{\mathrm{H} 1}$ and $D_{\mathrm{H} 3}$ had similar results in all evaluations. Thus, the choice of the hydraulic diameter equation depends on the geometry and the rheological model used. It was observed that for Fluid 1 Equations $D_{H_{1}}, D_{H_{2}}$, and $D_{\mathrm{H}_{3}}$ presented similar deviations for Annular I, which adopted the Power Law model. For Annular II, equations $D_{H 1}$ and $D_{\mathrm{H}_{3}}$ presented the best results.

Adopting Casson's rheological model for Fluid 1, it was observed that Equation $\mathrm{D}_{\mathrm{H} 2}$ presented deviations small them 20\%. For Annular I, Equations $D_{\mathrm{H} 1}$ and $D_{\mathrm{H} 3}$ presented the lowest deviation for Annular II. For Fluid 2, the equation for the hydraulic radius, $D_{\mathrm{H} 2}$, presented the lowest absolute deviance among all cases. The exception was Annular II, where Equations $D_{\mathrm{H} 1}$ and $D_{\mathrm{H} 3}$ had even smaller deviations.

Bailey and Peden (2000) quantified the correlation between the hydraulic diameter, fluid type, and rheological model. According to them, the hydraulic diameter can be corrected depending on the rheological model adopted by defining the effective diameter. For instance, in evaluating the pseudoplastic fluids one observes that the effective diameter is smaller than the physical diameter while for dilatant fluids the opposite occurs. 


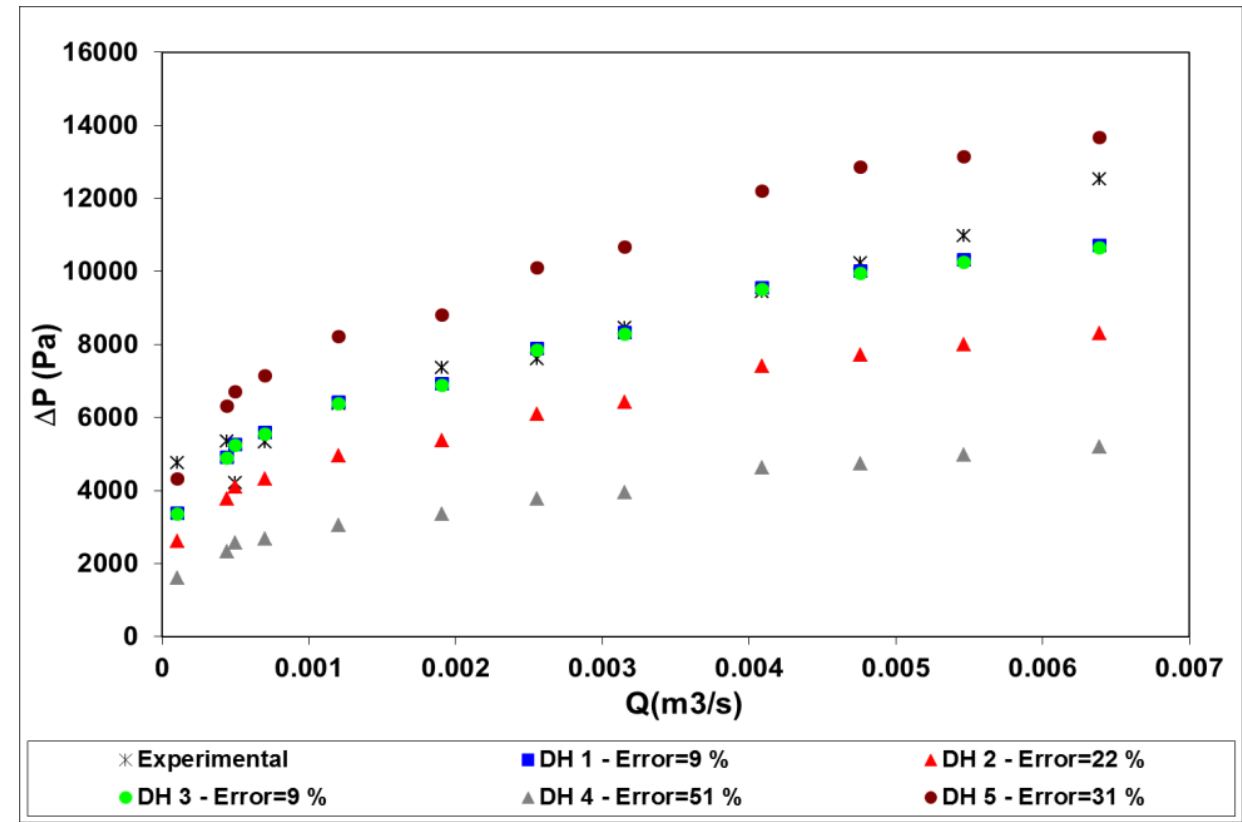

Figure 4. Evaluation of hydraulic diameter correlations using Power Law for Annular II in Fluid 1.

\subsection{Evaluation of correlation for friction in turbulent flow}

Equation 34 was used to determine the experimental friction factor. These results were compared with the results obtained by correlations presented in Equations 17 through 32. In those evaluations, the choice of the hydraulic diameter correlation depended on three things: the fluid's behavior, the rheological model, and the flow geometry. For the circular tube, Figure 5 presents experimental friction factor results for Fluid 1.
The brown straight line represents the laminar flow and was determined through Equation 35. The experimental data at turbulent flow were close to those obtained through the equations proposed by Gomes (1987).

Tables 9 through 12 present the average values of absolute error for the friction factor correlations obtained experimentally.

OWGomes's equation provided the best results when describing the friction factor at turbulent flow for Fluid 1 in the circular tube and adopting

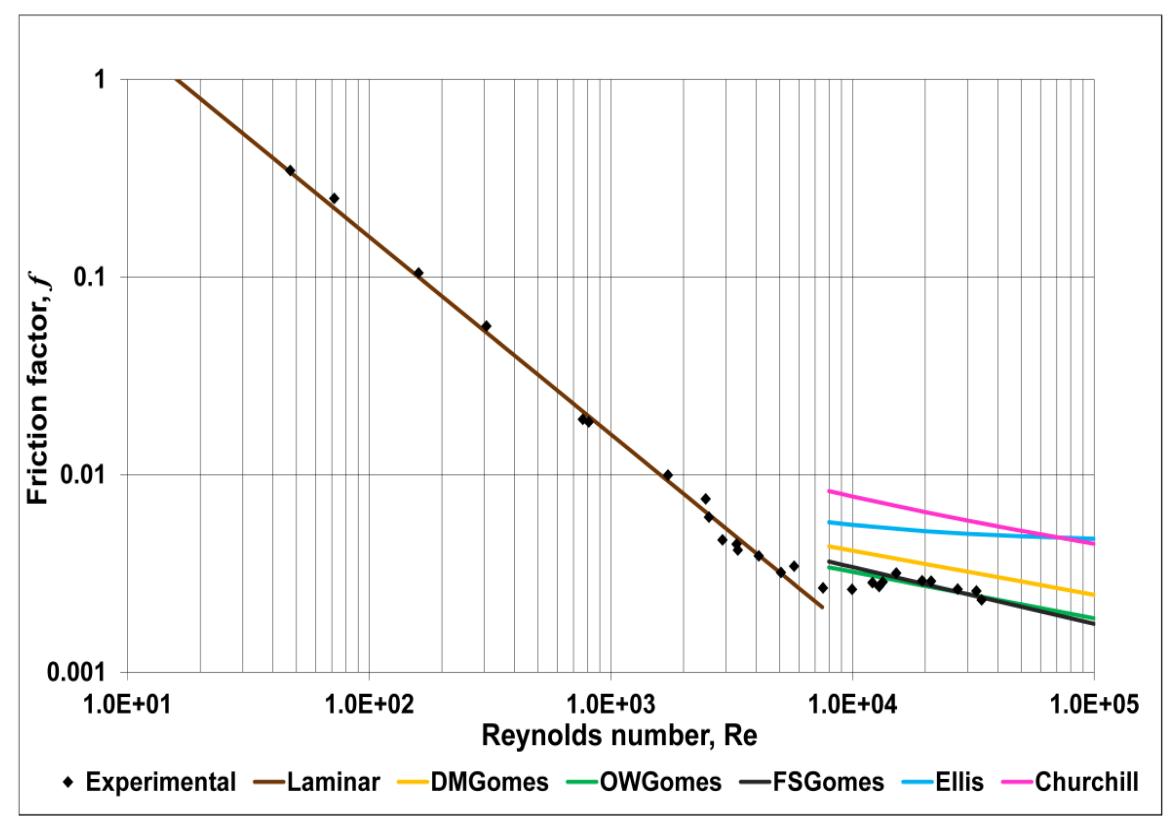

Figure 5. Friction factor for Fluid 1 in circular tube (Power Law). 
the Power Law model (Table 9). For Annular I, considering the same fluid and rheological model, the DMGomes's equation provided the best results (Table 9). At turbulent flow for Fluid 1 in the circular tube and using the Casson model, none of the equations was able to effectively describe the friction factor (Table 10). In this case, Darby and Melson's (1981) equation provided the smallest deviations. Ellis and George's (1977) equation for flow in Annular I provided the smallest deviations for Fluid 2, irrespective of the rheological model observed (Table 11 and 12). Churchill's (1977) equation provided the best results to describe the friction factor at turbulent flow in the circular tube (Table 11 and 12). For the annular tubes, the correlation presented by Ellis and George (1977) yielded the smallest absolute deviations. These equations are without the terms " $n$ " and "He".

For the two fluids and for all tube geometry studied in this work, the equations proposed by
Tomita (1959) and Churchill (1977) presented similar values of friction factor. Tomita's equation is only used for fluids that have yield stress.

According to the results, the friction factor equations with the smallest deviations for the circular tube differed from those for the annular tubes, considering always the same fluid and rheological model. This discrepancy may be due to friction factor equations not being directly dependent on the geometry of the tube. These correlations, functions of the Reynolds number, depend heavily on which equation of the hydraulic diameter is used, consequently causing the observed differences.

It was observed that Fluid 2 generated the greatest values in pressure drop. In this case, the correlations that present the smallest deviations were either Ellis and George's (1977) or Churchill's (1977), depending on the geometry which

Table 9. Average absolute errors of friction factors correlations for Fluid 1 using the Power Law model.

\begin{tabular}{cccccc}
\hline \multirow{3}{*}{ Geometry } & \multicolumn{5}{c}{$\sigma(\%)$} \\
\cline { 2 - 6 } & DM & OW & FS & \multirow{2}{*}{ Ellis } & \multirow{2}{*}{ Churchill } \\
& Gomes & Gomes & Gomes & & \\
\hline Circular & 37.89 & 9.39 & 11.95 & 93.87 & 149.67 \\
Annular I with $\mathrm{D}_{\mathrm{H} 1}$ & 7.97 & 19.71 & 13.89 & 32.81 & 92.03 \\
\hline
\end{tabular}

Table 10. Average absolute errors of friction factors correlations for Fluid 1 using the Casson model.

\begin{tabular}{cccccc}
\hline \multirow{2}{*}{ Geometry } & \multicolumn{5}{c}{$\sigma(\%)$} \\
\cline { 2 - 6 } & Tomita & $\begin{array}{c}\text { Darby } \\
\text { and Melson }\end{array}$ & $\begin{array}{c}\text { Darby } \\
\text { et. al. }\end{array}$ & Ellis & Churchill \\
\hline Circular & 108.71 & 36.40 & 58.02 & 82.13 & 107.67 \\
Annular I with $\mathrm{D}_{\mathrm{H} 2}$ & 34.41 & 62.78 & 20.30 & 14.66 & 34.56 \\
\hline
\end{tabular}

Table 11. Average absolute errors of friction factors correlations for Fluid 2 using the Power Law model.

\begin{tabular}{cccccc}
\hline \multirow{2}{*}{ Geometry } & \multicolumn{5}{c}{$\sigma(\%)$} \\
\cline { 2 - 6 } & DM & OW & FS & \multirow{2}{*}{ Ellis } & \multirow{2}{*}{ Churchill } \\
\hline Circular & 33.69 & 42.09 & 39.75 & 30.10 & 8.97 \\
Annular I with $\mathrm{D}_{\mathrm{H} 2}$ & 18.59 & 28.66 & 25.99 & 14.57 & 20.29 \\
Annular II with $\mathrm{D}_{\mathrm{H} 2}$ & 13.27 & 21.66 & 17.18 & 12.53 & 34.49 \\
\hline
\end{tabular}

Table 12. Average absolute errors of friction factors correlations for Fluid 2 using the Casson model.

\begin{tabular}{cccccc}
\hline \multirow{2}{*}{ Geometry } & \multicolumn{5}{c}{$\sigma(\%)$} \\
\cline { 2 - 6 } & Tomita & $\begin{array}{c}\text { Darby } \\
\text { and Melson }\end{array}$ & $\begin{array}{c}\text { Darby } \\
\text { et al. }\end{array}$ & Ellis & Churchill \\
\hline Circular & 13.92 & 75.95 & 53.80 & 34.86 & 13.87 \\
Annular I with $\mathrm{D}_{\mathrm{H} 2}$ & 16.57 & 68.41 & 44.69 & 16.56 & 17.03 \\
Annular II with $\mathrm{D}_{\mathrm{H} 1}$ & 43.70 & 61.60 & 30.08 & 9.19 & 44.54 \\
\hline
\end{tabular}


Table 13. Parameters of the new correlation for Fluid 1 using the Power Law model.

\begin{tabular}{lcccc}
\hline \multicolumn{1}{c}{ Geometry } & $\mathrm{A}$ & $\mathrm{B}$ & $\mathrm{C}$ & $\sigma(\%)$ \\
\hline Circular & 0.137 & 0.142 & -0.00106 & 5.86 \\
Annular I with $\mathrm{D}_{\mathrm{H} 1}$ & 0.0150 & -0.00277 & 0.149 & 5.30 \\
\hline
\end{tabular}

Table 14. Parameters of the new correlation for Fluid 1 using the Casson model.

\begin{tabular}{lcccc}
\hline \multicolumn{1}{c}{ Geometry } & $\mathrm{A}$ & $\mathrm{B}$ & $\mathrm{C}$ & $\sigma(\%)$ \\
\hline Circular & -0.663 & 0.671 & -0.000730 & 5.30 \\
Annular I with $\mathrm{D}_{\mathrm{H} 1}$ & 1.767 & -1.73 & 0.00189 & 7.37 \\
\hline
\end{tabular}

Table 15. Parameters of the new correlation for Fluid 2 using Power Law model.

\begin{tabular}{lcccc}
\hline \multicolumn{1}{c}{ Geometry } & $\mathrm{A}$ & $\mathrm{B}$ & $\mathrm{C}$ & $\sigma(\%)$ \\
\hline Circular & 0.617 & -0.600 & 0.00180 & 4.58 \\
Annular I with $\mathrm{D}_{\mathrm{H} 2}$ & 1.170 & -1.150 & 0.00130 & 5.88 \\
Annular II with $\mathrm{D}_{\mathrm{H} 2}$ & 1.789 & -1.760 & 0.00143 & 9.06 \\
\hline
\end{tabular}

Table 16. Parameters of the new correlation for Fluid 2 using the Casson model.

\begin{tabular}{lcccc}
\hline \multicolumn{1}{c}{ Geometry } & $\mathrm{A}$ & $\mathrm{B}$ & $\mathrm{C}$ & $\sigma(\%)$ \\
\hline Circular & 0.557 & -0.533 & 0.00311 & 4.47 \\
Annular I with $\mathrm{D}_{\mathrm{H} 2}$ & 0.868 & -0.840 & 0.00269 & 5.60 \\
Annular II with $\mathrm{D}_{\mathrm{H} 1}$ & 0.603 & -0.566 & 0.00589 & 9.58 \\
\hline
\end{tabular}

corresponds to the highest friction factor values. Otherwise, Fluid 1 produced the smallest pressure drop. As a result, the correlations that best fit were those with small friction factor values.

In the literature, the Casson model is commonly applied to describe fluids with the yield stress parameter, characterized by the Hedstron number. The correlations for friction factor that presented the smallest deviations for this model were those not having the Hedstrom number in its structure. This observation showed that in this case the yield stress of the fluids is not significant when calculating the friction factor.

\subsection{Proposal for new parameters for Ellis and George's correlation}

To achieve better results for the friction factor for real water-based drilling fluids investigated in this work, new parameters were proposed for the correlations presented in the literature. For instance, on average the correlation proposed by Ellis and George (1977), Equation 37, yielded the best results. Moreover, this equation has a very simple form.

$\mathrm{f}=\mathrm{A}+\mathrm{B} \times \mathrm{Re}^{\mathrm{C}}$

Where $A, B$, and $C$ are parameters.

As the geometry of the tube affects the choice of correlations, the parameters for those different geometries and different fluid formulation were reestimated. The parameter for re-estimation was performed using a nonlinear regression.

Tables 13 through 16 show the values of the estimated parameters and the average absolute error. The data shows that in all cases the new correlation fits better the experimental data.

Using the Power Law and Casson rheological models, the parameters obtained for the circular tube were quite different from those obtained for the annular tube. This nullifies any single equation that may describe the behavior of the friction factor for the three geometries and the two rheological models studied. 


\section{CONCLUSIONS}

Based on the results attained, one can conclude that the critical Reynolds number correlations do not generally match the experimental data. Moreover, the experimental method used to define the flow regime was inaccurate. In this case, the definition of the flow regime was affected strongly by the experimental critical point determination.

The selection of the hydraulic diameter equation depended on fluid type, rheological model, and tube geometry. In all cases, equations $D_{H 1}$ and $D_{H 3}$ gave similar results. In contrast, equations $D_{\mathrm{H} 4}$ and $D_{\mathrm{H} 5}$ presented unsatisfactory results.

A general conclusion that may be drawn from this work is that the performance of the friction factor correlations at turbulent flow depended also on fluid type, rheological model, as well as on the hydraulic diameter equation. Therefore, good results were obtained with the Ellis and George's (1977) correlation.

Finally, new parameters have been proposed for correlations presented in the literature using the fluids studied. For instance, Fluid 2 's best correlation was with that proposed by Ellis and George (1977). In this case, the new parameters adequately predicted the friction factors at turbulent flow in three different geometries using the Power Law and Casson rheological models for the two fluids examined.

\section{ACKNOWLEDGEMENTS}

We gratefully acknowledge the financial support provided by PETROBRAS, FINEP, CNPq, and CAPES.

\section{REFERENCES}

Bailey, W.J.; Peden, J.M. A Generalized and consistent pressure drop and flow regime transition model for drilling hydraulics. SPE Drill \& Completion, n.15, 2000.
Bertola, V.; Cafaro, E. Analogy between pipe flow of non-Newtonian fluids and 2-D compressible flow, J. Non-Newtonian Fluid Mechanics, v.109, p. 1-12, 2003.

Bourgoyne Jr, A. T.; Millheim, K. K.; Chenevert, M. E.; Young Jr, F. S. Applied drilling engineering. Second printing, Society of Petroleum Engineers, Richardson, Texas, 1991.

Churchill, S. W. Friction factor equation spans all fluid flow regimes. Chemical Engineering, v. 7, p. 91-92, 1977.

Craft, B. C. Well design, drilling and production. New Jersey: Prentice-hall, 1962.

Crittendon, B. C. The mechanics of design and interpretation of hydraulic fracture treatments. Journal of Petroleum Technology, v. 11, p. 21-29, 1959.

Darby, R.; Melson, J. How to predict the friction factor for the flow of Bingham plastics. Chemical Engineering, v. 88 (26), p. 59-61, 1981.

Darby, R.; Mun, R.; Borger, D. V. Predict Friction Loss in Slurry Pipes. Chemical Engineering, v.9, p.116, 1992.

Ellis, R. C.; George, D. S. Practical interpretation on theology, annular displacing torces. How to avoid by passing mud during primary cementing. World Oil, 64-69, 1977.

Escudier, M. P.; Oliveira, P. J.; Pinho, F.T. Fully developed laminar flow of purely viscous nonNewtonian liquids through annuli, including the effects of eccentricity and inner-cylinder rotation. International Journal of Heat and fluid Flow, v. 23, p. 52-73, 2002. http://dx.doi.org/10.1016/50142727X(01)00135-7

Gomes, F. J. A. D., Hydraulic, Power Law models, calculation method using rational polynomial models. Technical Meeting on Software Developing in Drilling Operations, CAPER/87, Salvador, Brazil, 1987. (in Portuguese).

Hanks, R.W. Laminar-turbulent transition for flow in pipes, concentric annuli, and parallel plates. AIChE Journal, v. 9 (1), p. 45-48, 1963. http://dx.doi.org/10.1002/aic.690090110 
Huilgol, R.R. A systematic procedure to determine the minimum pressure gradient required for the flow of viscoplastic fluids in pipes of symmetric cross-section. J. Non-Newtonian Fluid Mechanics, v. 136, p. 140-146, 2006. http://dx.doi.org/10.1016/i.jnnfm.2006.04.001

Lamb, H. S. Hydrodynamics. New York: Dover Publications, p. 586-187, 1945.

Metzner, A.B.; Reed, J.C. Flow non-Newtonian fluids correlation of laminar, transition and turbulent flow regions. AIChE Journal, v.1(4), p.434-440, 1955.

http://dx.doi.org/10.1002/aic.690010409

Mishra, P.; Tripathi, G. Transition from laminar to turbulent flow of purely viscous non-Newtonian fluids in tubes. Chemical Engineering Science, v.26, p. 915-921, 1971.

http://dx.doi.org/10.1016/0009-2509(71)83051-8

Pilehvari, A.; Serth, R. Generalized Hydraulic calculation method using rational polynomial model. J. Energy Resource Technology, 127, p.15, 2005. http://dx.doi.org/10.1115/1.1790536

Ryan, N. W.; Johnson, M. M. Transition from laminar to turbulent flow in pipes. AICHE Journal, v.5 (4), p.433-435, 1959.

http://dx.doi.org/10.1002/aic.690050407

Thomas, D. G. Non-Newtonian suspensions, Part I. Industrial and Engineering Chemistry, v.55 (11), p. 18-29, 1963.

http://dx.doi.org/10.1021/ie50647a004

Tomita, Y. A. A study of non-Newtonian flow in pipe lines. Bulletin of J. S. M. E., 2(5): 10-16, 1959. http://dx.doi.org/10.1299/isme1958.2.10 